\title{
Research on human performance evaluation model based on neural network and data mining algorithm
}

Wei Liang ${ }^{1,2}$ and Tingyi $\mathrm{Li}^{2^{*}}$

\author{
* Correspondence: \\ cuojiepangen1998@163.com \\ ${ }^{2}$ Division of Business Administration, \\ Wonkwang University, Iksan-si \\ 54538, Korea \\ Full list of author information is \\ available at the end of the article
}

\begin{abstract}
In order to effectively evaluate personnel performance, a distributed data mining algorithm for spatial networks based on BP neural wireless network is proposed. In the cloud computing environment, an excavator is used to construct multiple input multiple output spatial network data, analyze the data structure, and perform redundant data compression of massive data through time-frequency feature extraction. Combined with the adaptive matching filtering method, the characteristics of the data are matched. The spatial frequency feature extraction method is used to locate the features of the multiple-input multiple-output spatial network data. In order to improve the accuracy of data mining, the BP neural network is used to classify and identify the extracted data features to achieve the optimization of data mining. A wireless sensor network is a wireless network composed of a large number of stationary or moving sensors in a self-organizing and multi-hop manner. It cooperatively senses, collects, processes, and transmits the information of the perceived objects in the geographical area covered by the network and finally puts these The information is sent to the owner of the network. This algorithm improves the accuracy of personnel performance evaluation, simultaneously establishes a hierarchical analysis and quantitative evaluation model for the performance of government managers, and adjusts the results of hierarchical statistical analysis on government administrators as needed. The performance evaluation and optimization of government administrators were introduced. The empirical analysis results show that the method has higher accuracy for government managers' performance evaluation, higher efficiency of big data processing, and better integration.
\end{abstract}

Keywords: Analytic hierarchy process, Government administrators, Regression analysis, BP neural network, Wireless sensor networks

\section{Introduction}

The number of administrative departments of the government continues to merge with the reform of the government system and the development of the economy. No matter whether the scale of government administration is large or small, it is necessary to manage the performance of administrative staff. There are some difficulties in this part of the management. The administrative department of government is a non-profit organization. Under the situation of the reform of the government system and

(c) The Author(s). 2020 Open Access This article is licensed under a Creative Commons Attribution 4.0 International License, which permits use, sharing, adaptation, distribution and reproduction in any medium or format, as long as you give appropriate credit to the original author(s) and the source, provide a link to the Creative Commons licence, and indicate if changes were made. The images or other third party material in this article are included in the article's Creative Commons licence, unless indicated otherwise in a credit line to the material. If material is not included in the article's Creative Commons licence and your intended use is not permitted by statutory regulation or exceeds the permitted use, you will need to obtain permission directly from the copyright holder. To view a copy of this licence, visit http://creativecommons.org/licenses/by/4.0/. 
mechanism, its business scale is expanding constantly. The staff in the administration include the office, financial, and other aspects. Administrators, like staff in other departments, put the goals and interests of the executive branch at the top of their work. The performance management of administrative staff plays an important role in the development of administrative staff as well as the whole government administratio $\mathrm{n}[1]$. Fuzzy normal form neural network partly covers the basic knowledge of neural computation and fuzzy neural computation, and the realization of the algorithm can identify the essence of the relationship between the fuzzy system and neural network. The work of administrative staff is complicated, flexible, and difficult to quantify. Administrative staff provides more temporary services to other departments, such as manpower and finance. These temporary services are not easy to judge in quantitative management. The work of administrative personnel is complex and often receive other tasks in the work [2]. Fuzzy normal form system can provide big data support for medical health and reliable data source for decision-makers. In this paper, prov-s, safety data origin model based on W3CPROV, is proposed to study various labeled objects in the safety origin relation graph and define the range of related objects. Compared with the task of the production department, the work of the administrative staff is not restricted and directed by the production plan, and there is often sudden work in the daily work. This kind of sudden work can account for a large part of the total work of administrative personnel. The administrative personnel's work is too dynamic, and the examination will encounter problems of one kind or another [3].

The administrative staff's work content is more complex, mainly for the other departments of the government administrative department to provide services and help, and it also has the function of supervision and coordination [4]. The performance assessment of the administrative staff is not enough, and the quantitative process and the quantitative results are not clear and accurate. In the performance assessment of the administrative staff, the evaluation index is not flexible and does not take into account the differences between the administrative staff. Although the use of the unified assessment can save the cost for the government administration, it will strike the enthusiasm of the administrative staff [5]. Therefore, it needs to be studied. This paper proposes an effective performance evaluation model for government administrators. This paper puts forward the performance evaluation model of government administrators based on an analytic hierarchy process and combines the results of a descriptive statistical average analysis to test the sample regression of the large data of the performance evaluation of the government administrators and adopt the adaptive fuzzy scheduler. The law carries out the classification and recognition of the performance data of the government administrators [6]. According to the results of the performance information fusion of the government administrative personnel, the hierarchical analysis is carried out, the quantitative evaluation model of the performance of the administrative personnel of the government is established, and the regression analysis and adaptation of the administrative personnel management of the government are carried out by the F statistics analysis method. The adjustment, based on the hierarchical statistical analysis results of adaptive adjustment of government administrative personnel, combined with the AHP method, is to achieve the performance evaluation of government administrative personnel optimization. Finally, the empirical analysis of the 
performance test is taken, and it shows the superiority of this model in improving the ability of the performance evaluation of administrative personnel of the government $[7,8]$.

The rest of this paper is organized as follows. Section 2 discusses the statistical analysis model and constraint parameter analysis of the performance evaluation of government administrators, followed by optimization of the performance evaluation model for government administrators in Section 3. Empirical analysis and test are discussed in Section 4. Section 5 concludes the paper with a summary and future research directions.

\section{Statistical analysis model and constraint parameter analysis of the performance evaluation of government administrators}

2.1 Statistical analysis model of performance evaluation of government administrators

Performance management is a kind of concept put forward in the 1970s. Since it was put forward, all walks of life have carried on the thorough discussion to the performance management. In the 1990s of the last century, the theory of performance management matured gradually. In essence, performance management is a representative of ideas and concepts, and a series of problems related to enterprise performance are systematically considered around how to develop and operate effectively. Performance management involves enterprise planning, strategy, organization, strategic development, motivation, and leadership. Government administration is an organization that plays the role of guarantee and service in the management system, and it is also the organization that exerts the organizational function and the leading function. Therefore, the administration of the government to the top and bottom of the business activities, capital management, and other implementation coordination $[9,10]$.

First of all, it is necessary to construct the data sampling information flow model of government administrators' performance evaluation and combine the statistical characteristic analysis and descriptive statistical decision analysis method to model the performance evaluation of government administrators [11-13]. According to the above analysis, the overall implementation process of performance evaluation modeling of government administrators based on AHP is shown in Fig. 1.

The nonlinear statistical feature sequence analysis method is used to analyze the characteristics of the performance evaluation modeling data of the government administrators and the statistical modeling [14-16]. Firstly, the original data collection of the performance of the government administrators is carried out. By using the principal component characteristic analysis model method of the performance evaluation of the government administrative personnel, the regression test model of the performance evaluation model of the government administrative personnel is expressed as follows:

$$
G_{i}=\sum_{j} \alpha_{j} y_{i} y_{j} K\left(x_{i}, x_{j}\right)+y_{i} b-1
$$

Combined with the auto-regressive moving average (ARMA $(p, q))$ model for descriptive statistical analysis of large data government administrative personnel management effectiveness of the government administrative personnel to the statistical performance evaluation model for distribution, the equation is as follows: 


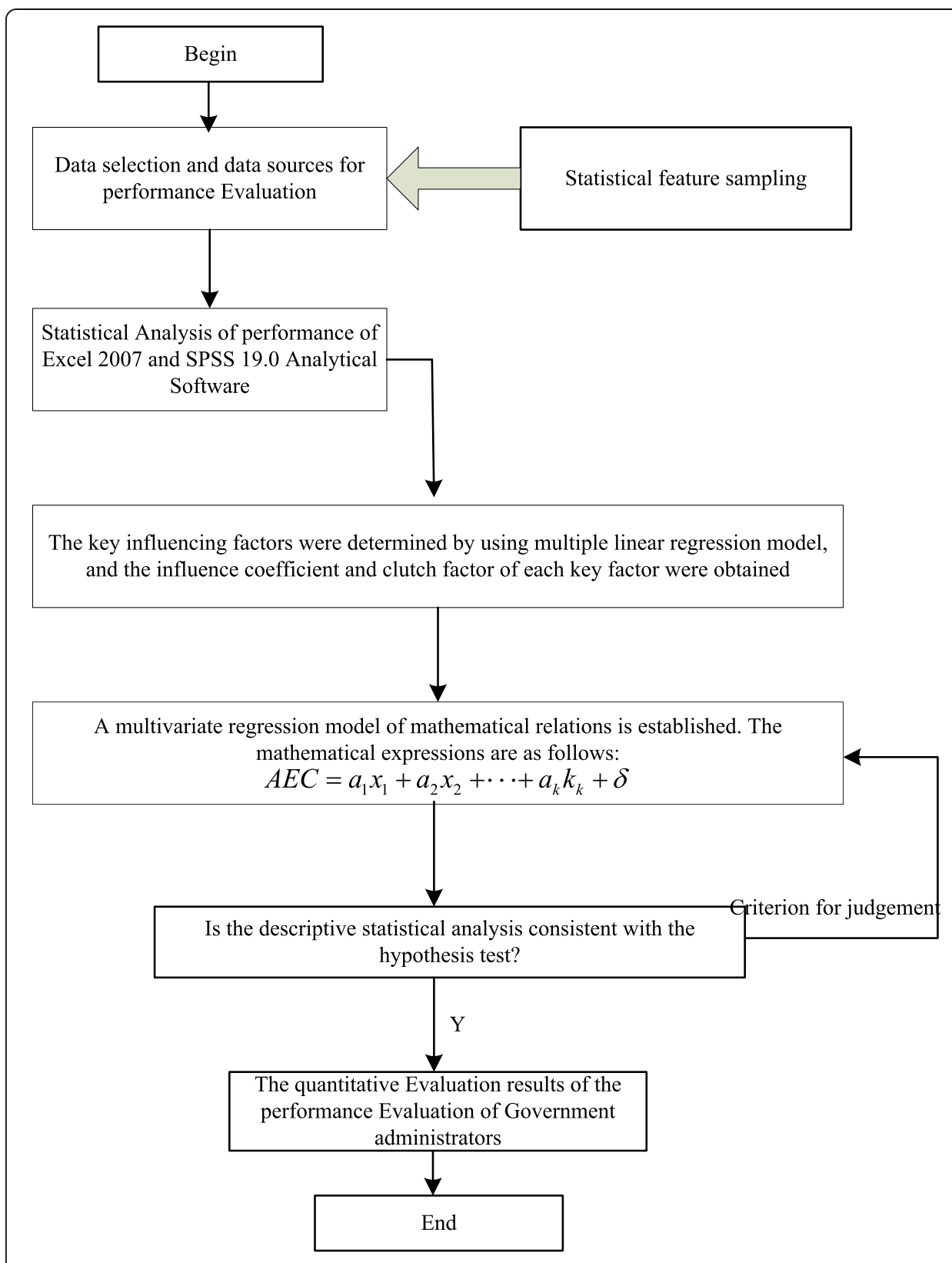

Fig. 1 Overall implementation process of performance evaluation modeling for government administrators based on AHP

$$
x_{n}=\phi_{0}+\sum_{i=1}^{p} \phi_{i} x_{n-i}+\sum_{j=0}^{q} \theta_{j} \eta_{n-j}
$$

In which, $\left\{\eta_{i}\right\}$ is the mean value of 0 , the variance is $\sigma^{2}$, and $\phi_{0}, \phi_{1}, \phi_{2}, \cdots \phi_{p}$ is the performance correlation distribution data of the government administrators. $\theta_{1}, \theta_{2}$, $\cdots \theta_{q}$ is called the descriptive statistical average coefficient of the government administrative staff management, and the statistical analysis method is used to match the characteristics. According to the statistical results of the above sample descriptive statistical analysis, the performance evaluation model of government administrators is established under the model of AHP [17-19]. 


\subsection{Analysis of the explanatory variables of the performance evaluation of government administrators}

On the basis of big data analysis of government administrative personnel management, the optimal design of the performance evaluation model of government administrative personnel is carried out, and a performance evaluation model of government administrative personnel based on hierarchical analysis is proposed in this paper. Combining the results of descriptive statistical average analysis, the regression test of the performance evaluation of government administrators is carried out, and the test statistics are obtained:

$$
Q=\frac{C_{1} \sum_{i=1}^{k} \exp \left[-S_{2}\left(V_{i}-\mu\right)^{2}\right]}{1+\exp \left[-S_{1} \sum_{i=1}^{k} w_{i}\left(T_{i}-V_{i}\right)\right]}
$$

In which, $C_{1}, S_{1}$, and $S_{2}$ are constant, indicating the decision-making statistical parameters of the performance of government administrators. By using $F$ test method, the characteristic statistical function of the optimal government administrators' performance decision is recorded as follows:

$$
S(i, j)=\frac{\sum_{u \in U_{i j}}\left(V_{u, i}-3\right)\left(V_{u, j}-3\right)}{\sqrt{\sum_{u \in U_{i j}}\left(V_{u, i}-\overline{V_{. i}}\right)^{2}} \sqrt{\sum_{u \in U_{i j}}\left(V_{u, j}-\overline{V_{. j}}\right)^{2}}}
$$

The adaptive fuzzy scheduling method is adopted to classify and identify the performance data of the government administrators, and the recognition function is expressed as follows:

$$
\min _{\omega, h, \zeta_{l}, \zeta_{l}^{*}}=\frac{1}{2} \omega^{T} \omega+c \sum_{i=1}^{l}\left(\zeta_{l}+\zeta_{l}^{*}\right)
$$

A hierarchical analysis and quantitative evaluation model of the performance of government administrators is established [20, 21]. Combined with the method of information fusion, the statistical distribution model of the optimal performance of government administrators is obtained as follows:

$$
\begin{gathered}
S n=\frac{\sum_{i}^{n} \max _{j=1}^{m} t_{i j}}{\sum_{i=1}^{n} n_{i}} \\
P P V=\frac{\sum_{j=1}^{m} \max _{i=1}^{n} t_{i j}}{\sum_{j=1}^{m} \sum_{i=1}^{n} t_{i j}}
\end{gathered}
$$

According to the results of descriptive statistical analysis, the effectiveness of the management of government administrators is evaluated, and a quantitative evaluation model of the performance of government administrators is established [22, 23]. 


\section{Methods}

\subsection{Construction of performance evaluation index of government managers}

The establishment of the evaluation index system is the basic condition to complete the performance evaluation of government managers. Constructing a scientific and effective evaluation index system needs the process of index primary selection, perfection to the final use, and so on $[24,25]$. The design of evaluation index system should follow the basic principles of "purpose, science, applicability, maneuverability, guidance, and credibility." According to the current evaluation criteria of cadres in our country, that are "ability, moral character, diligence, performance" standard, and combined with the actual work requirements of government administrators, this paper selects the following performance appraisal evaluation index system, including "Ability, Moral character, Performance, and Diligence," the four first-degree indicators [26, 27]. The specific meaning of the whole performance evaluation index system and its various indicator systems is shown in Table 1.

According to the survey of issuing the above indicators, this paper gives weight to each index of the performance evaluation of government management personnel and constructs the judgment matrix by using the weighted average summation method. The sum-product method is used to determine the weight coefficient of each judgment matrix $[28,29]$. Finally, through consistency detection, the detection process is as follows:

The processing results of the judgment matrix c are shown in Table 2.

Judgment matrix D-E processing results are shown in Table 3.

Table 1 Performance evaluation indicators for government managers

\begin{tabular}{|c|c|c|}
\hline & $\begin{array}{l}\text { Primary } \\
\text { indicator }\end{array}$ & Secondary index \\
\hline \multirow{19}{*}{$\begin{array}{l}\text { Performance evaluation indicators for government } \\
\text { managers }\end{array}$} & \multirow[t]{7}{*}{ Ability } & Working attitude \\
\hline & & Conscientiousness \\
\hline & & Event handling capability \\
\hline & & Innovation ability \\
\hline & & Other capabilities \\
\hline & & $\begin{array}{l}\text { Organizational management } \\
\text { capacity }\end{array}$ \\
\hline & & Capacity for policy analysis \\
\hline & \multirow[t]{5}{*}{ Moral character } & Political morality \\
\hline & & Professional ethics \\
\hline & & Ethics and morality \\
\hline & & Psychological morality \\
\hline & & Autonomy \\
\hline & \multirow[t]{3}{*}{ Performance } & Achievements in scientific research \\
\hline & & Daily performance \\
\hline & & Winning rate \\
\hline & \multirow[t]{4}{*}{ Diligence } & Attendance situation \\
\hline & & Load \\
\hline & & Work efficiency \\
\hline & & Degree of diligence \\
\hline
\end{tabular}


Table 2 Judgment matrix $B-C$

\begin{tabular}{lllllll}
\hline$B-C$ & $C_{1}$ & $C_{2}$ & $C_{3}$ & $C_{4}$ & $C_{5}$ & $A$ \\
\hline$C_{1}$ & 1.0000 & 1.0321 & 1.4555 & 1.2365 & 1.0000 & 0.2365 \\
$C_{2}$ & 0.6321 & 1.2236 & 1.0000 & 1.0000 & 1.2568 & 0.3214 \\
$C_{3}$ & 0.6540 & 1.0000 & 1.2635 & 1.3654 & 1.0000 & 1.0000 \\
$C_{4}$ & 0.8565 & 0.4526 & 0.4569 & 0.7569 & 1.9635 & 0.1652 \\
$C_{5}$ & 1.0000 & 0.3251 & 0.1358 & 0.5236 & 1.2365 & 0.1356 \\
\hline \multicolumn{7}{r}{ The $C R$ of the weight coefficient of the judgment matrix is less than 0.1, which satisfies the consistency detection. }
\end{tabular}

\subsection{AHP model for performance evaluation.}

Based on the above evaluation indicators, a performance evaluation model of government administrators is proposed based on AHP, establishes a quantitative evaluation model of hierarchical analysis and performance of government administrators, and adopts $F$ statistical analysis method to carry out government performance evaluation [30]: regression analysis and adaptive adjustment of administrative staff management, establishment of quantitative evaluation model of financial expenditure and performance of government administrators, adjustment of financing structure using $F$ statistic analysis method, administration based on AHP, and the fuzzy comprehensive decision function of the performance evaluation of the administrative personnel of the government [31, 32]:

$$
\mu_{B_{i}}=a_{B_{i}}+b_{B_{i}} \Delta+c_{B_{i}} \Phi
$$

In which, $a_{B_{i}}=\frac{B_{i}}{B_{U}+B_{v}}, b_{B_{i}}=\frac{\left(B_{U}-B_{i}\right)\left(B_{i}-B_{v}\right)}{\left(B_{U}+B_{v}\right) B_{i}}$, and $c_{B_{i}}=\frac{B_{U} B_{v}}{\left(B_{U}+B_{v}\right) B_{i}}$. According to the correlation analysis of the linear fitting results of the performance evaluation of the government administrative personnel, the linear fitting formula is expressed as follows:

$$
f(x)=\sum_{i=1}^{l}\left(a_{i}+a_{i}^{*}\right) k\left(x-x_{i}\right)+b
$$

According to the performance information fusion results of government administrators, the hierarchical analysis is carried out, and the constraint rules of performance evaluation are expressed as follows [33, 34]:

$$
\min (f)=\sum_{i=1}^{m} \sum_{j=1}^{n} C_{i j} X_{i j}
$$

Table 3 Judgment matrix D-E

\begin{tabular}{lllllll}
\hline$D-E$ & $D_{1}$ & $D_{2}$ & $D_{3}$ & $D_{4}$ & $D_{5}$ & $A$ \\
\hline$D_{1}$ & 1.0000 & 1.0355 & 1.1351 & 1.1656 & 1.0000 & 0.2235 \\
$D_{2}$ & 0.3651 & 1.2236 & 1.0000 & 1.0000 & 1.0356 & 0.3261 \\
$D_{3}$ & 0.6666 & 1.0000 & 1.2635 & 1.3546 & 1.0000 & 1.0000 \\
$D_{4}$ & 1.23565 & 0.4657 & 0.4566 & 0.6526 & 1.1386 & 0.1352 \\
$D_{5}$ & 1.0103 & 0.3246 & 0.1324 & 0.3103 & 1.1356 & 1.5686 \\
\hline \multicolumn{7}{l}{ The $C R$ of the weight coefficient of the judgment matrix is less than 0.1 , which satisfies the consistency detection. }
\end{tabular}




$$
\text { s.t }\left\{\begin{array}{l}
\sum_{j=1}^{m} X_{i j}=a_{i}, i=1,2 \cdots m \\
\sum_{i=1}^{m} X_{i j}=b_{i}, j=1,2 \cdots n \\
X_{i j} \geq 0, i=1,2 \cdots m, j=1,2 \cdots n
\end{array}\right.
$$

According to the above analysis, the adaptive fuzzy scheduling method is used to mine and evaluate the big data performance of government administrators.

\subsection{Quantitative evaluation of the performance of government administrators}

By using $F$ statistic analysis method, the regression analysis of government administrative personnel management is carried out, and the pre-progressive weighting coefficient of performance evaluation is obtained as follows:

$$
\begin{aligned}
& C W_{\text {min }}^{n}= \begin{cases}\left(\left(1-B_{l(n)}\right) e^{1-\alpha_{n}}+B_{l(n)}\right) \times C W_{\text {min }}^{l(n)}, \alpha_{n}>1 \\
C W_{\text {min }}^{l(n)}, & 0 \leq \alpha_{n} \leq 1\end{cases} \\
& B_{l(n)}=\left(1 /\left(1+\bar{D}_{l(n)-1))^{X}}\right.\right. \\
& \alpha_{n}= \begin{cases}\left|D_{n}\right| /\left(\bar{D}_{l(n)}\right), & \bar{D}_{l(n)} \neq 0 \\
0, & \bar{D}_{l(n)}=0\end{cases}
\end{aligned}
$$

In which, $\alpha_{n}$ is the asynchronous iterative coefficient of the performance evaluation of the government administrators, and $B_{l(n)}$ is the error adjustment coefficient of the performance evaluation of the government administrators:

$$
\begin{aligned}
& (1+\bar{D})^{M}>1 \\
& A / C W_{\text {min }}^{0}>1
\end{aligned}
$$

Combined with the analytic hierarchy process, the gray scale quantification coefficient of the performance evaluation is satisfied:

$$
x>0
$$

If $\left(1+\overline{D_{l_{i}}}\right)^{X}>1$, the performance evaluation characteristics of the output meet the following requirements:

$$
C W_{\min }^{l_{i+1}}>C W_{\min }^{l_{i}}
$$

Because

$$
\begin{aligned}
& 0<\left(1-B_{l(n)}\right) e^{1-\alpha_{n}}<1-B_{l(n)} \\
& B_{l(n)}<\left(1-B_{l(n)}\right) e^{1-\alpha_{n}}+B_{l(n)}<1
\end{aligned}
$$

Thus, the time inversion statistical correlation coefficient of the performance evaluation modeling of government administrators is obtained as follows:

$$
\left(\left(1-B_{l(n)}\right) e^{1-\alpha_{n}}+B_{l(n)}\right) \times C W_{\min }^{l(n)}>C W_{\min }^{l(n)-1}
$$

While $\alpha_{m}>1$, then: 


$$
C W_{\min }^{l(n)}>C W_{\min }^{l(m)}>C W_{\min }^{m}
$$

While $\alpha_{m} \leq 1$ 时, then:

$$
C W_{\min }^{n}=C W_{\min }^{l(n)}>C W_{\min }^{l(m)}=C W_{\min }^{m}
$$

The convergence function of performance evaluation satisfies:

$$
C W_{\min }^{n}>C W_{\min }^{m}
$$

It can be seen that the statistical characteristic quantity of performance evaluation is greater than the threshold value, and the performance evaluation model of government administrators constructed in this paper is bounded convergent.

\section{Experiment}

The experiment adopts Matlab 7, the method of sampling the data of government administrative personnel's performance evaluation modeling adopts the method of social investigation and descriptive statistical analysis. The software of data analysis is SPSS 19.0. The basic statistical results of the personnel are shown in Table 4. Figure 2 is the distribution diagram of network nodes.

According to the above descriptive statistical analysis results, the regression analysis of performance evaluation is carried out, and the results of regression analysis are shown in Table 5. Figure 3 shows the variation of latency with the network size.

According to the results of the regression analysis of performance evaluation in Table 5 , the performance evaluation of government administrators is carried out. The distribution of the evaluation curve is shown in Fig. 4, taking the satisfaction degree of the masses and administrative behavior as the parameter.

The analysis shows that the performance evaluation of government administrators by using this model is accurate and the confidence level is better.

Table 4 Basic information of government administrators

\begin{tabular}{lllll}
\hline Statistical characteristics & & Quantity & Effective percentage & Cumulative percentage \\
\hline Career & Administration & 123 & 42.76 & 48.45 \\
& Technology & 43 & 14.87 & 61.56 \\
Working time & Rear services & 57 & 38.75 & 53.23 \\
& Less 1 year & 86 & 29.44 & 26.22 \\
& 1-3 years & 83 & 41.53 & 65.34 \\
Sex & More than 3 years & 55 & 30.54 & 42.21 \\
\multirow{5}{*}{ Educational background } & College and below & 32 & 19.65 & 71.21 \\
& Male & 55 & 28.54 & 32.21 \\
& Undergraduate course & 82 & 70.92 & 19.23 \\
Age & Master's degree or above & 43 & 18.21 & 70.43 \\
& Under 30 & 54 & 72.24 & 43.33 \\
& 30-40 & 43 & 23.35 & 72.45 \\
& Over 40 years of age & 58 & 4.65 & 92.45 \\
\hline
\end{tabular}




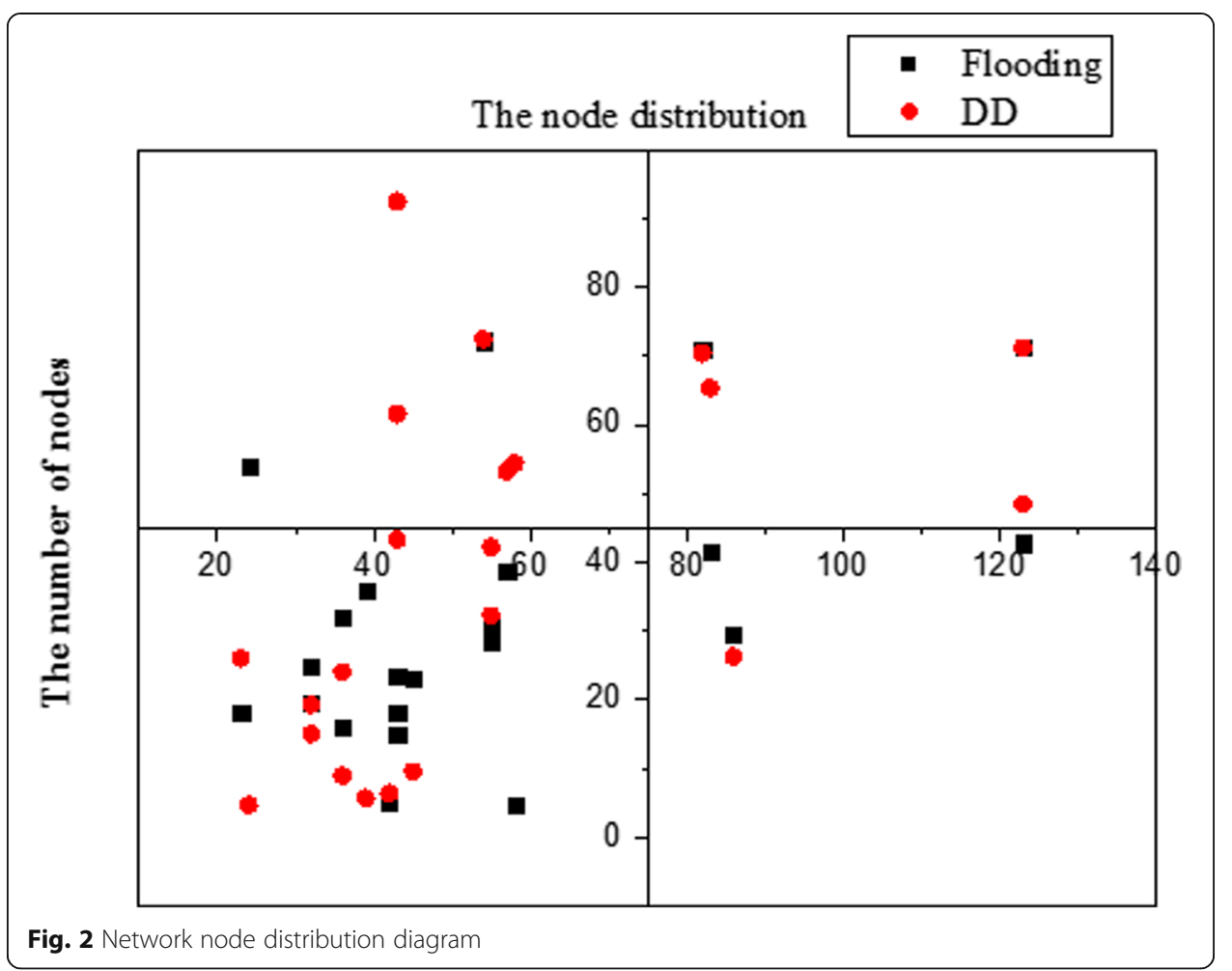

In order to further verify the effectiveness of the performance evaluation model of this paper, the quantitative evaluation method, the relative evaluation method, and the scale evaluation method are compared, as shown in Fig. 5.

\section{Results and discussion}

In this paper, a performance evaluation model of government administrators based on AHP is proposed. Combined with the results of descriptive statistical average analysis, the sample regression test of big data performance evaluation of government administrators is carried out, and the adaptive fuzzy scheduling method is used to classify and identify the performance big data of government administrators. According to the results of the performance information fusion of government administrators, the hierarchical analysis and the quantitative evaluation model of the performance of government administrators are established. The $F$ statistic analysis method is used for the regression analysis and adaptive adjustment of the government administrative personnel management, and the adaptive adjustment for the government administrative

Table 5 Regression model coefficient table for performance evaluation

\begin{tabular}{|c|c|c|c|c|}
\hline \multirow[t]{2}{*}{ Factors } & \multicolumn{2}{|c|}{ Standardization coefficient } & \multicolumn{2}{|c|}{ Collinear statistics } \\
\hline & Coefficient & Standard error & Tolerance & Variance inflation factor \\
\hline Constant & 3.432 & 0.054 & - & - \\
\hline$F 3(x 1)$ & 0.354 & 0.043 & 0.545 & 1.543 \\
\hline$F 4(x 2)$ & 0.532 & 0.021 & 0.656 & 1.212 \\
\hline$F 6(x 3)$ & 0.345 & 0.023 & 0.653 & 1.554 \\
\hline$F 7(x 4)$ & 0.233 & 0.045 & 0.932 & 1.432 \\
\hline
\end{tabular}



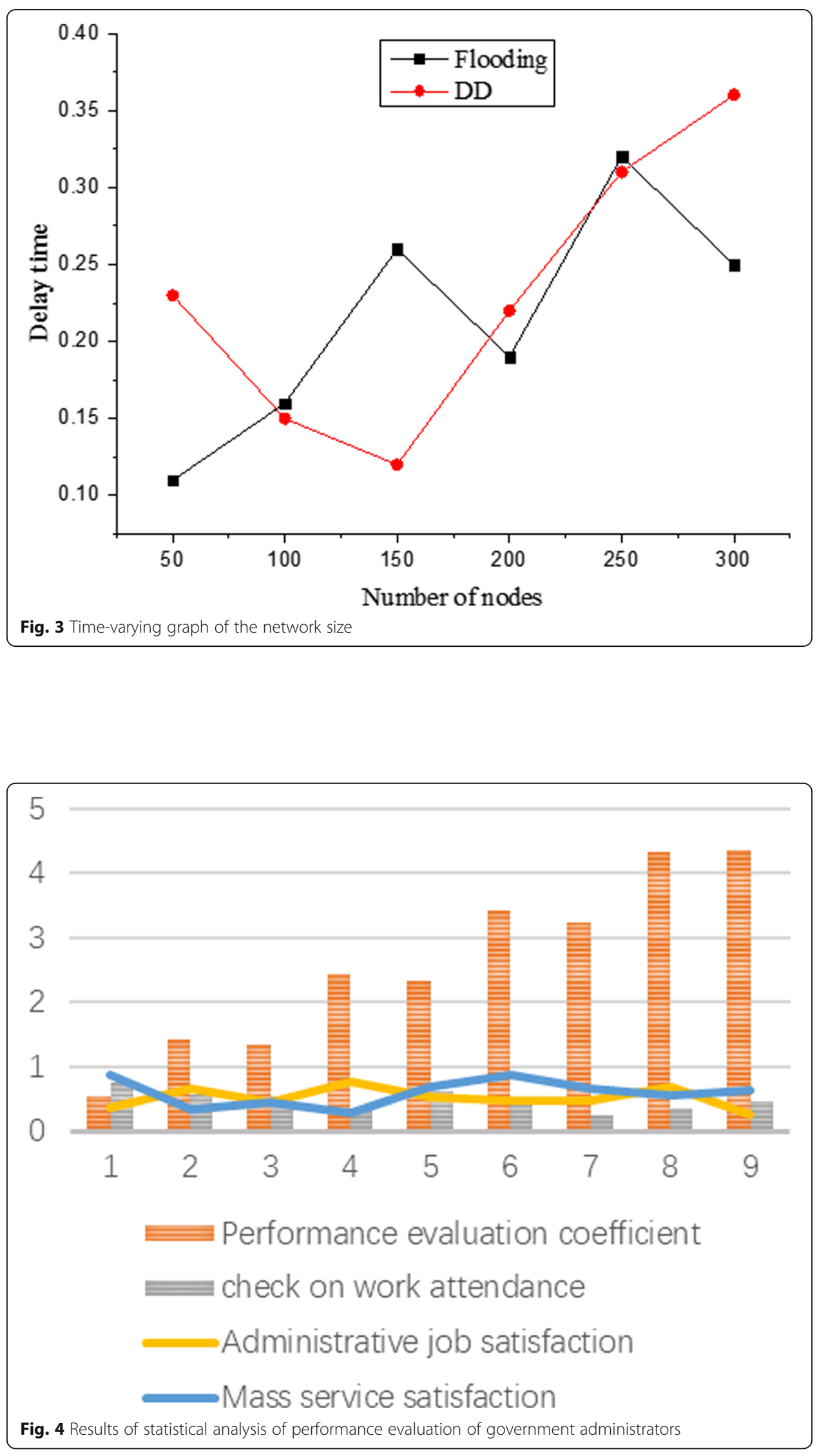


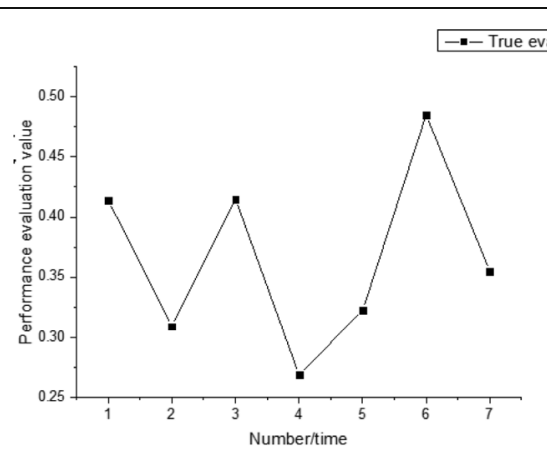

(a) Quantitative evaluation method

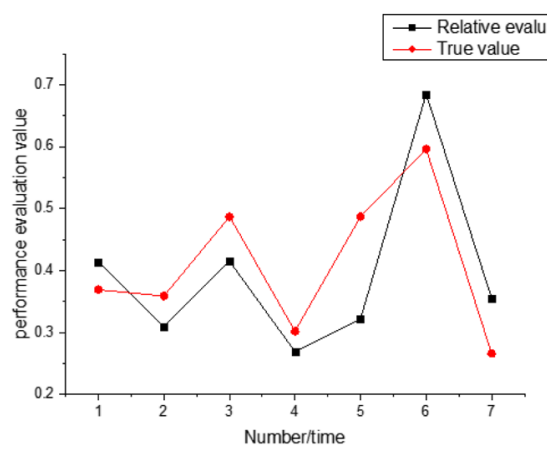

(b) Relative evaluation method

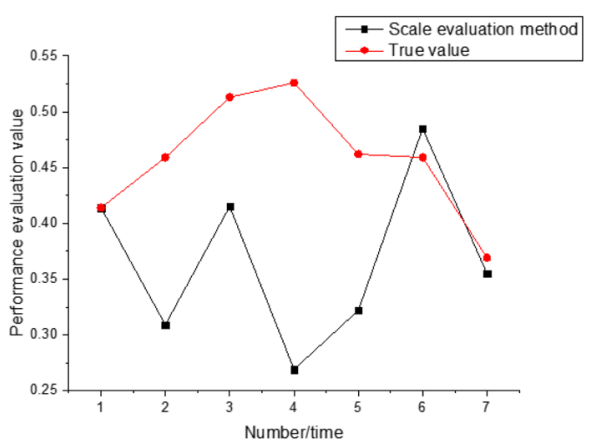

(c) Scale evaluation method

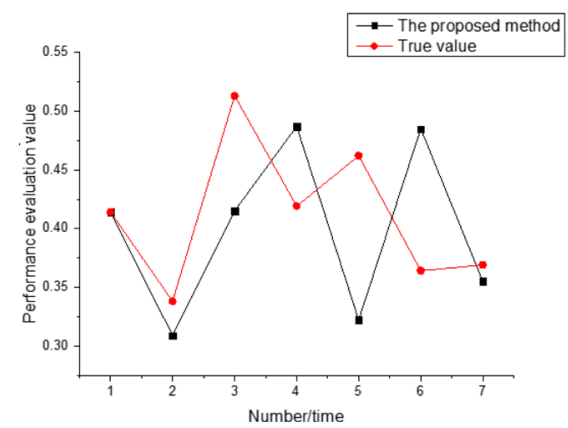

(d) The proposed method

Fig. 5 Performance measurement comparison of different methods. a Quantitative evaluation method. b Relative evaluation method. c Scale evaluation method. $\mathbf{d}$ The proposed method 
personnel is carried out according to the results of the hierarchical statistical analysis, and combined with the AHP method, the performance evaluation and optimization of government administrators is realized. The results of the empirical analysis show that the performance evaluation of government administrators by using this method has higher accuracy, higher efficiency of big data processing, and better integration. This method has a good application value in the performance evaluation of government managers.

Abbreviations

AHP: Analytic hierarchy process

\section{Acknowledgements}

None

Authors' contributions

WL wrote the entire article. TL is responsible for the experimental simulation. The authors read and approved the final version of the manuscript.

\section{Funding}

None

Availability of data and materials

The datasets used and/or analyzed during the current study are available from the corresponding author on reasonable request.

\section{Ethics approval and consent to participate}

This article does not contain any studies with human participants or animals performed by any of the authors. All authors agree to submit this version and claim that no part of this manuscript has been published or submitted elsewhere.

\section{Competing interests}

The authors declare that they have no conflict of interest.

* Research involving human participants and/or animals

\section{Author details}

${ }^{1}$ Shandong Agriculture and Engineering University, Jinan 250100, China. ${ }^{2}$ Division of Business Administration, Wonkwang University, Iksan-si 54538, Korea.

Received: 22 March 2020 Accepted: 14 August 2020

Published online: 10 September 2020

\section{References}

1. J.F. Zheng, J. Zhang, K.Y. Zhu, Gust front statistical characteristics and automatic identification algorithm for CINRAD. Acta Meteorologica Sinica 28(4), 607-623 (2014)

2. Y. Hwang, T.Y. Yu, V. Lakshmanan, Neuro-fuzzy gust front detection algorithm with S-band polarimetric radar. IEEE Transact Geosci Remote Sensing 55(3), 1618-1628 (2017)

3. E. Shi, Q. Li, D.Q. Gu, Z.M. Zhao, Weather radar echo extrapolation method based on convolutional neural networks. J Comput Appl 38(3), 661-665 (2018)

4. T.D. Fletcher, H. Andrieu, P. Hamel, Understanding, management and modelling of urban hydrology and its consequences for receiving waters, a state of the art. Adv Water Resourc 51(1), 261-279 (2013)

5. J.Y. Xue, X.Y. Ni, On the reform of college English teaching under the trend of educational informatization. Integr Inform Technol Teach Pract 45(12), 43-45 (2015)

6. B.F. Zheng, X.F. Gu, Walk through the "Cloud" end of practical education information--on the application of cloud platform in English teaching. Educ Teach Forum 12(03), 263-265 (2016)

7. S. Wei, L. WYNTER, A new one-level convex optimization approach for estimating origin-destination demand. Transportation. Res Part B Methodol 46(10), 1535-1555 (2012)

8. C.S. Rao, K.C.K. Reddy, D.S. Rao, Power control technique for efficient call admission control in advanced Wireless Networks. Int J Comput Sci Eng 4(6), 962-973 (2012)

9. H.Y. Shi, W.L. Wang, N.M. Kwok, Game theory for wireless sensor networks: a survey. Sensors 12(7), 9055-9097 (2012)

10. G.P. Zhang, P. Liu, E.J. Ding, Energy efficient resource allocation in non-cooperative multi-cell OFDMA systems. J Syst Eng Electron 22(1), 175-182 (2011)

11. B. Ma, X.Z. Xie, H.P. Psho, An efficient proactive spectrum handover mechanism in cognitive radio networks. Wirel Person Commun 79(3), 1-23 (2014)

12. Y.G. Ji, Y.T. Li, C. Shi, Aspect rating prediction based on heterogeneous network and topic model. J Comput Appl 37(11), 3201-3206 (2017)

13. H.J. Sun, H. Zhang, J.J. Wu, Correlated scale-free network with community: modeling and transportation dynamics. Nonlinear Dynamics 69(4), 2097-2104 (2012) 
14. A.Q. Bi, S.T. Wang, Transfer affinity propagation clustering algorithm based on Kullback-Leiber distance. J Electron Inf Technol 38(8), 2076-2084 (2016)

15. X.L. Xiong, L.X. Yang, Y.Z. Ma, Z.B. Zhuang, Alerting algorithm of low-level wind shear based on fuzzy C-means. J Comput Appl 38(3), 655-660 (2018)

16. H. Bo, L.C. Shu, M.M. Yu, Performance evaluation of the Taiwan railway administration. Ann Oper Res 259(1-2), 119-156 (2017)

17. S. Mutereko, F. Ruffin, Public administration dilemmas: an analysis of teachers' perceptions of the effects of performance evaluation in post-colonial South Africa. Int J Public Admin 41(1), 1-12 (2016)

18. A.J. Million, Indispensable institutions: making a case for public libraries as local E-government service administrators. Bull Assoc Inform Sci Technol 42(2), 11-16 (2016)

19. J.H. Li, Y. Lei, Research on the optimization design of public sector performance evaluation based on analytic hierarchy process. Agro Food Indust Hi Tech 28(1), 1627-1631 (2017)

20. X. Fan, Research on validity evaluation framework of college internal control based on AHP and FCE. Rev Facultad De Ingenieria 32(3), 440-447 (2017)

21. Z. Xie, R. Lin, J. Wang, W. Hu, L. Miao, Vicarious learning: how entrepreneurs enhance a firm's international competitiveness through learning from interlocking director network partners. Front. Psychol.. https://doi.org/10.3389/ fpsyg.2020.00689(2020)

22. Y.H. Chang, P.C. Shao, H.J. Chen, Performance evaluation of airport safety management systems in Taiwan. Safety Sci 75(5), 72-86 (2015)

23. W. Su, L. Zhao, S. Deng, Developing a performance evaluation model of Organic Rankine Cycle for working fluids based on the group contribution method. Energy Conver Manag 132, 307-315 (2017)

24. G. Szárnyas, B. Izsó, I. Ráth, The Train Benchmark: cross-technology performance evaluation of continuous model queries. Soft Syst Model, 1-29 (2017)

25. M. Shao, Y. Song, B. Wu. The supplier selection of the marine rescue equipment based on the analytic hierarchy process (AHP)-limited diversity factors method. Polar Biol 20(20), 259-272(2018).

26. J. Zhang, X. U. Xiu, Ming D. A condition assessment method of power transformers based on fuzzy analytic hierarchy process. Power Syst Protect Control 3(75), 75-81(2016).

27. C. Qin, Y. Zhang, Evaluation of the safety of mine road based on fuzzy analytic hierarchy process. J Trans Technol 07(1), 70-82 (2017)

28. R. Fatchurrahman, H. Putra, I. Joyokusumo, Light sensor selection of Wi-MoLS (wireless modern light sensor) based on analytic hierarchy process (AHP)//Industrial, Mechanical, Electrical, and Chemical Engineering. IEEE, 152-155 (2017)

29. M. Abdel-Basset, M. Mai, Y. Zhou, Multi-criteria group decision making based on neutrosophic analytic hierarchy process. J Intell Fuzzy Syst 33(6), 4055-4066 (2017)

30. C. Xu, A novel recommendation method based on social network using matrix factorization technique. Inform Process Manag 54(3), 463-474 (2018)

31. W.X. Xin, J.G. Hou, L.Y. Ming, Quantitative characterization of vertical heterogeneity of mouth bar based on the analytic hierarchy process and the fuzzy mathematics: a case study of Guan 195 fault block of Wangguantun Oilfield. Nat Gas Geosci 28(12), 1914-1924 (2017)

32. Z. Huang, J. Tang, G. Shan, J. Ni, Y. Chen, C. Wang, An efficient passenger-hunting recommendation framework with multi-task deep learning. IEEE Internet of Things Journal (2019)

33. Y. Wang, E. Zio, X. Wei, D. Zhang, B. Wu, A resilience perspective on water transport systems: the case of Eastern Star. Int J Disas Risk Reduct 33, 343-354 (2019)

34. M. Zhang, D. Zhang, F. Goerlandt, X. Yan, P. Kujala, Use of HFACS and fault tree model for collision risk factors analysis of icebreaker assistance in ice-covered waters. Safety Sci 111(4), 128-143 (2019)

\section{Publisher's Note}

Springer Nature remains neutral with regard to jurisdictional claims in published maps and institutional affiliations.

\section{Submit your manuscript to a SpringerOpen ${ }^{\circ}$ journal and benefit from:}

- Convenient online submission

- Rigorous peer review

- Open access: articles freely available online

- High visibility within the field

- Retaining the copyright to your article

Submit your next manuscript at $\mathbf{s p r i n g e r o p e n . c o m ~}$ 